\title{
Performance of different photocatalytic oxidation processes in petroleum wastewater treatment: A Comparative Study
}

\author{
Aljuboury D.A.D.A. ${ }^{1,}{ }^{,}$, Palaniandy P. ${ }^{1}$, Abdul Aziz H. ${ }^{1}$, Feroz S. ${ }^{2}$ and Abu Amr S.S. ${ }^{3}$ \\ ${ }^{1}$ School of Civil Engineering, Universiti Sains Malaysia, Malaysia \\ ${ }^{2}$ Caledonian College of Engineering, Oman. \\ ${ }^{3}$ Environmental Engineering Technology Department, Malaysian Institute of chemical and Bioengineering Technology, Universiti Kuala \\ Lumpur, (UniKL, MICET), 78000, Melaka, Malaysia. \\ Received: 26/07/2016, Accepted: 30/11/2016, Available online: 30/03/2017 \\ *to whom all correspondence should be addressed: \\ e-mail:msc.dheeaa@yahoo.com
}

\section{Abstract}

The present study was conducted to compare the performance of different solar photocatalytic processes $\left(\mathrm{TiO}_{2}\right.$ photocatalysis, photo-Fenton, photo-Fenton coupled with $\mathrm{TiO}_{2}$ photocatalysis, and photo-Fenton coupled with $\mathrm{TiO}_{2} / \mathrm{ZnO}$ photocatalysis) for the treatment of petroleum wastewater. The removal efficiency of chemical oxygen demand (COD) is evaluated. $\mathrm{TiO}_{2}$ dosage and $\mathrm{pH}$ are the main factors that improve the $\mathrm{COD}$ removal in the $\mathrm{TiO}_{2}$ photocatalysis process while $\mathrm{Fe}^{+2}$ and $\mathrm{H}_{2} \mathrm{O}_{2}$ concentration are the main factors in photo-Fenton process. The photoFenton coupled with $\mathrm{TiO}_{2} / \mathrm{ZnO}$ photocatalysis is the most efficient process for treatment of petroleum wastewater at the neutral conditions ( $\mathrm{pH} 7$ ). Therefore, no need to adjust $\mathrm{pH}$ during this treatment. In acidic conditions $(\mathrm{pH}<7)$, the photo-Fenton process is more efficient than the $\mathrm{TiO}_{2}$ photocatalysis process while it is less efficient than the $\mathrm{TiO}_{2}$ photocatalysis process in alkaline conditions $(\mathrm{pH}>7)$.

Keywords: $\mathrm{TiO}_{2}$ photocatalysis process; Photo-Fenton process; photo-Fenton coupled with $\mathrm{TiO}_{2}$ photocatalysis process; photo-Fenton coupled with $\mathrm{TiO}_{2} / \mathrm{ZnO}$ photocatalysis processes; the petroleum wastewater.

\section{Introduction}

One of the major problems facing industrialized nations is contamination of the environment by hazardous chemicals. A wide range of pollutants are detected in petroleum wastewater in Sohar oil refinery. Therefore, the elimination of these chemicals from petroleum wastewater is presently one of the most important aspects of pollution control in Oman.

Advanced oxidation processes (AOPs) have capability of rapid degradation of recalcitrant pollutants in the aquatic environment. They have shown high efficiency to remove the organic compounds from effluents even when they are present at low concentrations (Philippopoulos and Poulopoulos 2003; Da Silva et al., 2015; Masomboon et al., 2010; Paz et al., 2013). In addition, they didn't form environmentally hazardous byproducts. Remediation of hazardous substances is attributed to hydroxyl radical, which has the potential to destroy and degrade toward organic (Hermosilla et al., 2009; Malato et al., 2001).

When $\mathrm{TiO}_{2}$ expose to sunlight in the $\mathrm{TiO}_{2}$ photocatalysis, a hole in the valence band and an electron in the conduction band are generated by light induction. This hole cause the oxidation of hydroxyl ions and produce the hydroxyl radicals at the $\mathrm{TiO}_{2}$ surface. While in the photo-Fenton process, formation of hydroxyl radicals base on reaction between $\mathrm{Fe}^{+2}$ and $\mathrm{H}_{2} \mathrm{O}_{2}$ under sunlight irradiation.

The AOPs have shown promising results in treatment of non-biodegradable and toxic compounds (Boundjou et al., 2012). They consider techniques for the treatment of polluted water because they are eco-friendly, fast, effective, and able to completely oxidize organic molecules at a low energy cost (Kwon et al., 2008).

The reactions with hydroxyl radicals can be triggered by several ways depending on the structure of the organic compounds, electron transfer, abstraction of hydrogen atom, and electrophilic (Philippopoulos and Poulopoulos 2003; Legrini et al., 1993). The major drawbacks of Fenton process are iron complexation by carboxylic intermediates. But these complexes can be photo-activated by photoFenton process and additional hydrogen peroxide ( $\mathrm{HO}^{\circ}$ ) generation (Amor et al., 2015; Diyauddeen et al., 2011). Therefore, the photo-Fenton experiments are applied to treat petroleum wastewater.

The solar photo-Fenton is based on using solar radiation to increase production of hydroxyl radicals $(\bullet \mathrm{OH}$ ) (Amor et al., 2015; Fernandez et al., 2014; Lucas and Peres, 2009; Pignatello et al., 2006). Using solar energy in AOPs can reduce processing costs and make it more affordable for commercial use (Amor et al., 2015).

Several previous studies have reported the enhanced oxidation of contaminants by the $\mathrm{TiO}_{2}$ photocatalysis process and the photo-Fenton coupled with $\mathrm{TiO}_{2}$ photocatalysis. Tony et al., (2009) reported that the Fenton/ $/ \mathrm{TiO}_{2} / \mathrm{UV}$ process achieved an $84 \%$ COD removal in 
the diesel oil-water emulsion while the Fenton/ZnO/UV process resulted in a reduction of about $18 \%$ in the COD removal efficiency. This result might be because the surface area of $\mathrm{TiO}_{2}$ was more than that for $\mathrm{ZnO}$. Duran and Monteagudo, (2007) found that the $\mathrm{pH}$ and $\mathrm{TiO}_{2}$ concentration were the main factors for the photo-Fenton coupled with $\mathrm{TiO}_{2}$ photocatalysis process at an acidic conditions. While Nogueira et al., (2004) showed that the roles of $\mathrm{TiO}_{2}$ was less important than that of iron and $\mathrm{H}_{2} \mathrm{O}_{2}$ in the degradation of 4CP and DCA by the $\mathrm{TiO}_{2}$ photocatalysis process. Kim et al., (2012) reported that the $\mathrm{TiO}_{2}$ photocatalysis process increased COD removal at $\mathrm{pH}$ (6.5-7.5). Rossiter et al., (2013) showed that the 53\% COD removal was achieved by the photo-Fenton process from petroleum wastewater at an acidic conditions ( $\mathrm{pH} 3.5)$.

The main aims for this study are as follows:

- To compare of the homogenous and the heterogeneous photocatalysis processes such as the photo-Fenton, the $\mathrm{TiO}_{2}$ photocatalysis, the photo-Fenton coupled with $\mathrm{TiO}_{2}$ photocatalysis, and the photo-Fenton coupled with $\mathrm{TiO}_{2} / \mathrm{ZnO}$ photocatalysis processes.

- To assess treatment efficiencies and the main factors for these processes by "A central composite design (CCD) with response surface methodology (RSM)".

\section{Materials and methods}

\subsection{Wastewater Characterization}

The samples are collected from the point that the petroleum wastewater is just leaving the dissolved air flotation (DAF) unit in the Sohar oil refinery (SOR). Samples of the petroleum wastewater are collected in different days. Samples are transferred to the laboratory and stored under refrigeration $\left(4{ }^{\circ} \mathrm{C}\right)$ until use. The petroleum wastewater characterization is determined by the quantification of $\mathrm{pH}$ and COD according to the Standard Methods for the Examination of Wastewater Methodology. COD is measured by COD photometer (manufactured by $\mathrm{CHEMetrics}$ ). The $\mathrm{pH}$ levels are monitored by using a digital $\mathrm{pH}$ meter. COD is estimated before and after treatment. The characteristics of the petroleum wastewater are summarized in Table 1.

Before each analysis, samples are filtered by filter papers $(0.22 \mu \mathrm{m}$ Millipore Durapore membrane, 40 ashless, Diameter $150 \mathrm{~mm}$ ). Solar ultraviolet radiation (UV) is measured by a global UV radiometer (KIPP \& ZONEN).

Table 1. Characteristics of the petroleum wastewater from Sohar oil refinery (SOR)

\begin{tabular}{ccccc}
\hline No & Parameter & $\begin{array}{c}\text { Range of } \\
\text { concentrations }\end{array}$ & Average & $\begin{array}{c}\text { The standard } \\
\text { discharge limit* }\end{array}$ \\
\hline 1 & $\mathrm{pH}$ & $6-8$ & 7 & $6-9$ \\
\hline 2 & $\mathrm{COD}(\mathrm{ppm})$ & $550-1600$ & 1075 & $150-200$ \\
\hline
\end{tabular}

*Wastewater discharge standard of Oman (2005)

\subsection{Materials}

The catalysts are $\mathrm{ZnO}$ and $\mathrm{TiO}_{2}$ Aeroxide $\mathrm{P}-25$ (manufactured by Evonik Industries $C_{0}$ in Germany).
Samples of the petroleum wastewater are collected from Sohar oil refinery (SOR). Hydrogen peroxide $\left(\mathrm{H}_{2} \mathrm{O}_{2}\right)(35 \%$ $(\mathrm{v} / \mathrm{v}))$ and iron sulfate hydrate $\left(\mathrm{FeO}_{12} \mathrm{~S}_{3}\right)$ are supplied by EMPROVE Exp (USA.). Sulfuric acid (95-97\%) and sodium hydroxide $(50 \%)$ are used to adjust the $\mathrm{pH}$ to the desired values.

\subsection{Experimental procedure}

A sketch of the photocatalysis processes is shown in Figure 1. It consists of the tubular solar reactor (four tubes $(50 \mathrm{~cm}$ length $\times 2 \mathrm{~cm}$ inner diameter $\times 0.1 \mathrm{~cm}$ thickness)) and a glass recirculation tank $(5 \mathrm{~L})$, which is subjected to stirring. The UV-Index is calculated as follow:

The output from the UV-E radiometer is taken according to ISO 17166:1999/CIE S007/E-1998. Transform the output voltage to $\mathrm{W} \mathrm{m}^{-2}$ with the instruments sensitivity. Equation (1) allows calculating the amount of UV intensity received on any surface in the same position with regard to the sun by UV-Index (UVI):

$$
U V I=R\left(W m^{-2}\right) * 40\left(m^{2} W^{-1}\right)
$$

Where:

- UVI is the UV-Index.

- $\mathrm{R}$ is the reading $(\mathrm{R})$ in UV radiometer by $\left(\mathrm{W} / \mathrm{m}^{2}\right)$ unit.

The tubular photo reactor operate at a UV-index of 9 (according to Exposure category is very high) as shown in figure S1.

The solution is re-circulated through the reactor at a flow rate of about $1.51 \mathrm{~min}^{-1}$ by means of a peristaltic pump. The added materials and their concentrations such as $\mathrm{TiO}_{2}$, $\mathrm{ZnO}, \mathrm{H}_{2} \mathrm{O}_{2}$ and $\mathrm{Fe}^{+2}$ depend on used process. The $\mathrm{pH}$ for petroleum wastewater samples is used between 3 and 8 . Several sets of experiments are carried out according to CCD with RSM to determine the COD removal efficiency under the optimum operational conditions.

At the end of each run, the samples are withdrawn and then kept them at rest for $\mathbf{3 0} \mathrm{min}$ in order to avoid iron precipitation in the reactor. The major iron ion is precipitated by increasing the $\mathrm{pH}$ of sample to (8) because the Fenton process stops at pH 8 (Abu Amr et al., 2013).

Tekin et al., (2006) showed that the treatment efficiency of Fenton ceased when the $\mathrm{pH}$ was equal to or greater than 7 because the generation of hydroxyl radicals were reduced due to lack of presence free iron ions.

The excess of hydrogen peroxide $\left(\mathrm{H}_{2} \mathrm{O}_{2}\right)$ is removed by adding $\mathrm{MnO}_{2}$. The suspension is stirred until the formation $\mathrm{O}_{2}$ is finished (no bubbles on surface) (Herrmann, 1996). The presence of $\mathrm{H}_{2} \mathrm{O}_{2}$ normally provokes accurate COD values (Amor et al., 2015).

\subsection{Mathematical modeling}

CCD and RSM are employed in the statistical design of the experiments, data analysis, explaining the optimal conditions and assessment of the relationship among significant independent variables such as $\mathrm{pH}$, catalyst dosage, and reaction time. 
The adequacy of the proposed models for COD removal from the petroleum wastewaters by these processes is evaluated at the optimum conditions. Each independent variable is varied over three levels $(-1,0,+1)$ according to face centered CCD. The total number of experiments conducts for the four factors according to Equation (2) and for the five factors according to Equation (3) to assess the pure error and got a good estimate.

$$
\begin{aligned}
& \text { No. of Experiments }=2^{k}+2 k+6 \\
& \text { No. of Experiments }=2^{k}+2 k+8
\end{aligned}
$$

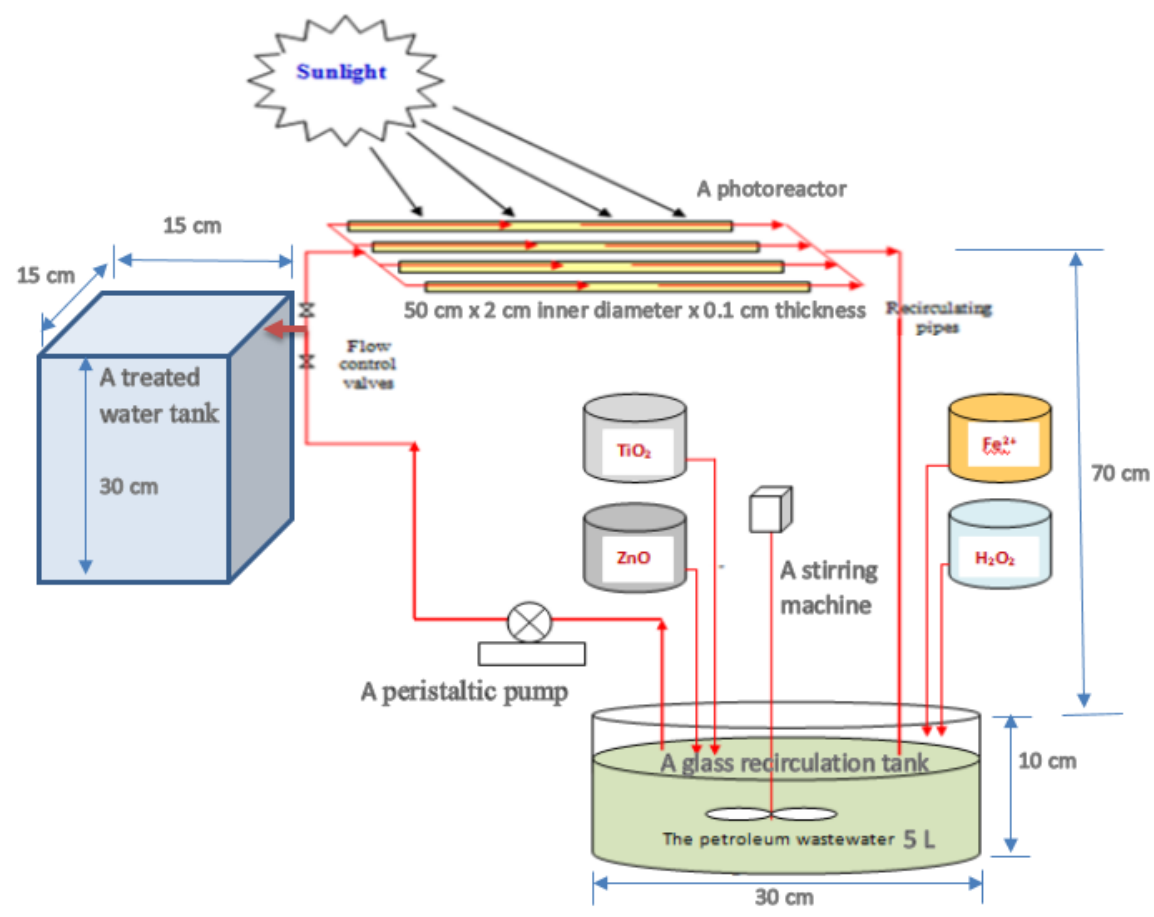

Figure 1. A sketch of the photocatalysis processes

The design consists of factorial points $\left(2^{k}\right)$, axial points $(2 \mathrm{k})$ and 6 or 8 replications for a center point. In this work, the total numbers of experiments conduct for the four and five factors are 30 and 50, respectively. The COD removal is the dependent variable (response) during these processes.

The behavior of the system is explained through an empirical second-order polynomial model, as shown in Equation (4): (Montgomery, 2008)

$$
\begin{aligned}
& Y=B_{0}+\sum_{j=1}^{k} \beta_{j} X_{j}+\sum_{j=1}^{k} B_{j j} \\
& X_{j}^{2}+\sum_{i} \sum_{<j=2}^{k} B_{i j} X_{i} X_{j}+e_{i}
\end{aligned}
$$

Where;

$Y$ is the response.

$X_{i}$ and $X_{j}$ are the variables.

$B$ is the regression coefficient.

$\mathrm{k}$ is the number of factors studied and optimize in the experiment.

$\mathrm{e}_{i}$ is the random error.
The analysis of variance (ANOVA) is used for graphical analysis of data to obtain the interaction between the process variables and the responses. The qualities of the fit polynomial models are expressed by coefficient of determination $\left(R^{2}\right)$. Models terms are evaluated by the $P$ value (probability) with 95\% confidence level.

All the response surface quadratic models for parameters are significant at the $5 \%$ confidence level since the $P$-values are less than 0.05 . The $R^{2}$ values for the COD removal rates are greater than the cut-off (0.80) for a model with a good fit. A high $R^{2}$ value ensures a satisfactory adjustment of the quadratic model to the experimental data and illustrates good agreement between the calculated and observed results (Abu Amr et al., 2013).

If the model terms have the $P$-value (probability) more than 0.05 , they are considered a limited influence. Thus, they must be excluded from the study to improve the models according to literature. The models of COD removal are considered significant using the $F$-test at $5 \%$ significant level (Prob < 0.05).

The AP ratio is a measure of the "signal to noise ratio". If the AP ratio values are higher than 4, they are a desirable values and confirm that the predicted models can be used to navigate the space defined by the CCD according to literature (Noordin et al., 2004). 


\section{Results and discussion}

\subsection{Effect of $p H$}

The $\mathrm{pH}$ not only affects the surface charge of the catalyst particles, but also influences the positions of conduction and valence bands in a semiconductor. Moreover, industrial wastewater may be discharged at various $\mathrm{pH}$, which make the photocatalytic process more complicated.

Results obtained from experiments with varying $\mathrm{pH}$ from 3.5 to 8 are shown in figure 2 . According to the results, the photo-Fenton process is more efficient than the $\mathrm{TiO}_{2}$ photocatalysis process in acidic conditions $(\mathrm{pH}<7)$ for petroleum wastewater treatment.

As shown in figure 2, the photo-Fenton coupled with $\mathrm{TiO}_{2} / \mathrm{ZnO}$ photocatalysis process improved performance the $\mathrm{TiO}_{2}$ photocatalysis process and the photo-Fenton process at neutral conditions $(\mathrm{pH}$ 7) for petroleum wastewater. By comparing the photo-Fenton process with the photo-Fenton coupled with $\mathrm{TiO}_{2}$ photocatalysis process at neutral conditions, the COD removal is improved from $27 \%$ to $38 \%$, respectively. This enhancement is attributed to increasing of the hydroxyl radicals $(\bullet \mathrm{OH})$ production by the presence of $\mathrm{TiO}_{2}$ (Hermosilla et al., 2009).

The COD removal is observed to be faster in alkaline $\mathrm{pH}$ than in acidic $\mathrm{pH}$ range, this is attributed to negative surface of the $\mathrm{TiO}_{2}$ with $\mathrm{OH}^{-}$ions, which acts as an efficient trap for the photo-generated holes and produces hydroxyl radicals Equation (5) (Khan et al., 2015; Jamil et al., 2015).

$$
\mathrm{OH}_{\text {surface }}+\mathrm{h}^{+}{ }_{\mathrm{vb}} \rightarrow \mathrm{OH}_{\text {surface }}
$$

Interpretation of such negative impact of the $\mathrm{pH}$ on the current $\mathrm{TiO}_{2}$ /organic matters interaction is a very difficult task in terms of many organic pollutants and intermediates existing in the petroleum wastewater. However, attempts have been made to explain this phenomenon. The $\mathrm{pH}$ effect is related to the point of zero charge (pzc) of $\mathrm{TiO}_{2}$ at pH 6.28 (Chou and Liao, 2005; Alaton et al., 2002; Shahrezaei et al., 2012).
In acidic media $(\mathrm{pH}<6.2)$, the surface of $\mathrm{TiO}_{2}$ is positively charged, whereas it is negatively charged under alkaline conditions ( $\mathrm{pH}>6.2$ ) (Fernandez et al., 2002; Gogniat et al., 2006) according to Equations (6) and (Malato et al., 2001);

$$
\begin{array}{ll}
\mathrm{TiOH}+\mathrm{H}^{+} \leftrightarrow \mathrm{TiOH}^{2+} & \mathrm{pH}<6.2 \\
\mathrm{TiOH}+\mathrm{OH}^{-} \leftrightarrow \mathrm{TiO}^{-}+\mathrm{H}_{2} \mathrm{O} & \mathrm{pH}>6.2
\end{array}
$$

When the operating $\mathrm{pH}$ is below the $\mathrm{pH}$ at $\mathrm{PZC}$ (TiO2), the surface charge for the catalyst becomes positive and gradually exerts an electrostatic attraction force towards the negatively charged compounds. Such polar attractions between $\mathrm{TiO} 2$ and charged anionic organic compounds can intensify the adsorption onto the photon activated $\mathrm{TiO} 2$ surface for subsequent photocatalytic reactions (Chong et al., 2010). This is particularly significant when the anionic organic compounds are present at a low concentration level.

At operating $\mathrm{pH}$ above the $\mathrm{pH}$ at $\mathrm{PZC}$ ( $\mathrm{TiO} 2)$, the catalyst surface will be negatively charged and repel the anionic compounds in water (Gogate and Pandit, 2004). Gogate and Pandit, (2004) reported that the influence of initial $\mathrm{pH}$ on the photocatalytic process is more complex and the observed effect is generally dependent on the type of pollutant and the PZC of the photocatalyst used during the oxidation process. The $\mathrm{pH}$ of the medium influences the properties of a surface charge of the photocatalyst. Thus, it has a significant effect on the electrostatic interaction between the catalyst surface and the pollutant molecules.

By comparing these results with previous studies, the results of this work are agreement with some studies. Tony et al., (2009) have reported that the neutral pH of the oilwater solution was the optimum $\mathrm{pH}$ value for $\mathrm{COD}$ removal by the Fenton/ $\mathrm{TiO}_{2} / \mathrm{UV}$ system. However, Kim et al., (2012) showed that the synergistic removal of benzoic acid by the $\mathrm{UV} / \mathrm{TiO}_{2} / \mathrm{Fe}^{+3} / \mathrm{H}_{2} \mathrm{O}_{2}$ system was very efficient at the $\mathrm{pH}$ values ranging from 4 to 7 but the addition of $\mathrm{Fe}^{+3}$ and $\mathrm{H}_{2} \mathrm{O}_{2}$ to the UV/TiO 2 system caused the negative effects at higher $\mathrm{pH}$ values $(\mathrm{pH}>7)$.

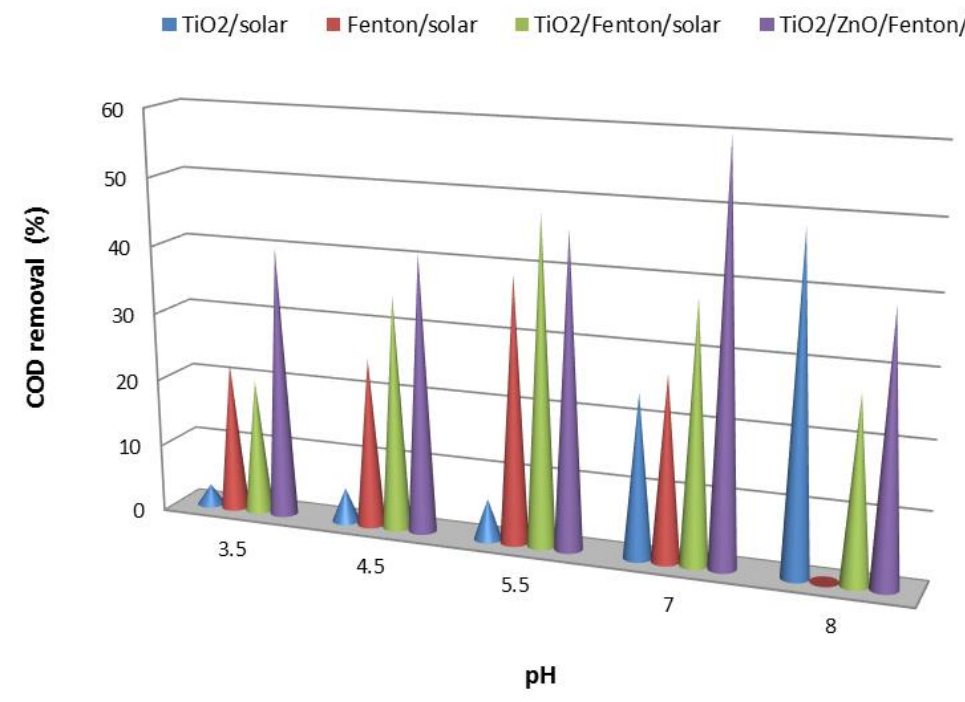

Figure 2. Comparing the four applications for COD removal under different $\mathrm{pH}$ values 


\subsection{Effect of Fenton reagent}

In this study, the $\mathrm{COD}$ removal for the $\mathrm{TiO}_{2}$ photocatalysis process in petroleum wastewater is improved clearly by using Fenton reagent with it in the photo-Fenton coupled with $\mathrm{TiO}_{2}$ photocatalysis process as shown in figure 3 . The rapid COD removal is attributed to high hydroxyl radical $(\bullet \mathrm{OH})$ concentrations, which exhibit reactivity toward organic compounds (De Luna et al., 2013). In the photoFenton coupled with $\mathrm{TiO}_{2}$ photocatalysis process, Fenton ions react with $\mathrm{H}_{2} \mathrm{O}_{2}$ to form hydroxyl radicals $(\bullet \mathrm{OH})$ as shown in Equation (8):

$$
\mathrm{Fe}^{+2}+\mathrm{H}_{2} \mathrm{O}_{2} \rightarrow \mathrm{Fe}^{+3}+\mathrm{OH}^{-}+\mathrm{OH}
$$

At the second stage (after $90 \mathrm{~min}$ ) $\mathrm{Fe}^{2+}$ ions are decreased and the excess amount of hydrogen peroxide can cause the auto decomposition of $\mathrm{H}_{2} \mathrm{O}_{2}$ to oxygen and water, and the recombination of hydroxyl radicals. In addition, the excess of $\mathrm{H}_{2} \mathrm{O}_{2}$ reacts with hydroxyl radical $(\bullet \mathrm{OH})$ in result to slower rate of production hydroxyl radical $(\bullet \mathrm{OH})$ (De Luna et al., 2013). Therefore, the COD removal is decreased by reducing hydroxyl radical concentrations (Tony et al., 2009).

\subsection{Effect of $\mathrm{ZnO}$ concentration}

The experiments are conducted to investigate the benefits of augmenting the photo-Fenton coupled with $\mathrm{TiO}_{2}$ photocatalysis process with $\mathrm{ZnO}$. It is clear from figure 2 that the use of $\mathrm{ZnO}$ increases the COD removal efficiency of the photo-Fenton coupled with $\mathrm{TiO}_{2} / \mathrm{ZnO}$ photocatalysis process at the neutral value of $\mathrm{pH}$ (7) for treatment of petroleum wastewater. This result may be attributed to the increase of the surface area of the photocatalysis process and an increase of the number of active sites available for adsorption (Al-Sayyed et al., 1991; Alhakimi et al., 2003). In addition, Several researchers have reported that $\mathrm{ZnO}$ has larger band-gap (3.2-3.7 eV) which favours the absorption at a wide range of solar spectrum and more light quanta than other semiconducting metal oxides (like $\mathrm{TiO}_{2}$ ) (Tony et al., 2009; Sakthivel et al., 2003; Daneshvar et al., 2004).

\subsection{Effect of $\mathrm{TiO}_{2}$ concentration}

It is well known that $\mathrm{TiO}_{2}$ has a wide band-gap $(\sim 3.2 \mathrm{eV})$ and is only excited by UV-light, thus, it is inactive under visible light irradiation. This feature of $\mathrm{TiO}_{2}$ diminishes the utilization of solar energy as a sustainable energy source for its excitation because only $5 \%$ of the incoming solar energy on the earth's surface is in the UV range. For this reason, in recent years, in order to utilize sunlight instead of UV irradiation, studies have begun to develop the next generation of $\mathrm{TiO}_{2} \mathrm{~S}$, well-tailored photocatalysts with high photocatalytic activities under visible light irradiation.

The COD removal in petroleum wastewater increases when the $\mathrm{TiO}_{2}$ concentration increases until the optimum $\mathrm{TiO}_{2}$ dosages in the $\mathrm{TiO}_{2}$ photocatalysis process and the photoFenton coupled with $\mathrm{TiO}_{2}$ photocatalysis process. The optimum $\mathrm{TiO}_{2}$ dosages for these processes are $\mathrm{I} \mathrm{g}^{-1}$ and $0.66 \mathrm{gl}^{-1}$, respectively.

But the $\mathrm{TiO}_{2}$ dosages after the maximum value have a negative effect in these processes. Where the excess $\mathrm{TiO}_{2}$ particles increase turbidity of solution and cause decreasing the penetration of light into the solution and the scattering of the light resulting in a reduction in production of the hydroxyl radicals $(\bullet \mathrm{OH})$ at the $\mathrm{TiO}_{2}$ surface (Gaya and Abdullah, 2008). Thus, the higher dose of catalyst may not be useful due to reduce penetration of light and decrease the removal efficiency beyond a certain limit (Wang et al., 2004; Kabir et al., 2010).

\subsection{Applying the optimum conditions}

The optimum catalysts concentrations and $\mathrm{pH}$ of the solution are $0.7 \mathrm{~g} \mathrm{l}^{-1} \mathrm{TiO}_{2}, 0.3 \mathrm{~g} \mathrm{l}^{-1} \mathrm{ZnO}, 1.46 \mathrm{~g} \mathrm{l}^{-1} \mathrm{H}_{2} \mathrm{O}_{2}, 0.01$ $\mathrm{g}^{-1} \mathrm{Fe}^{+2}$ and $\mathrm{pH}$ (7) in the photo-Fenton coupled with $\mathrm{TiO}_{2} / \mathrm{ZnO}$ photocatalysis process, which is the most efficient in the neutral conditions. The COD removal for this process, under the optimum conditions, is more than $60 \%$ at $180 \mathrm{~min}$ (RT) as shown in figure 3.

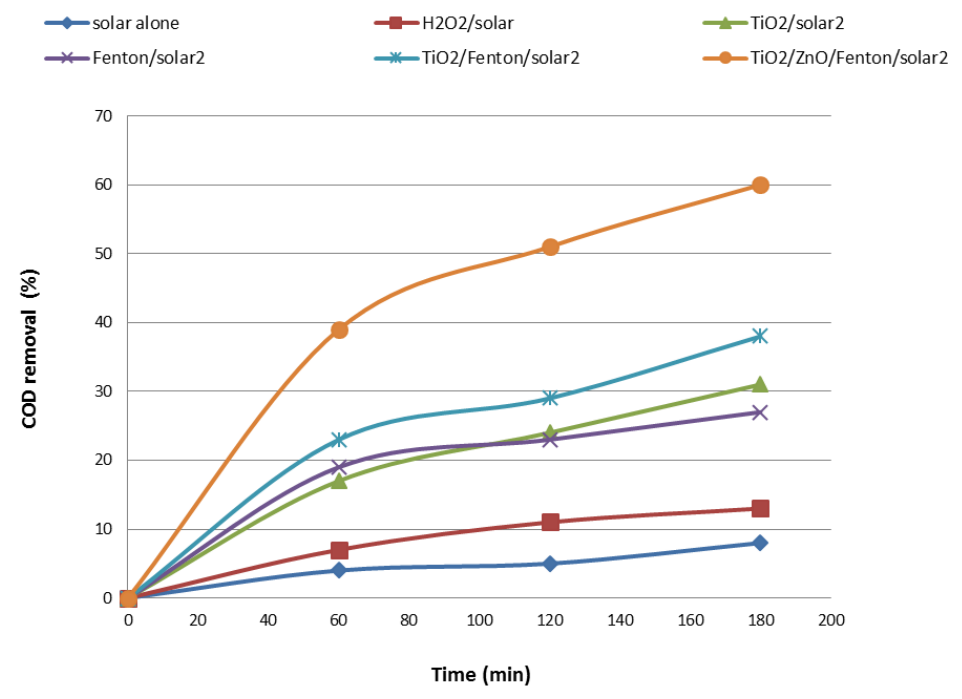

Figure 3. Comparing different processes for COD removal under $\mathrm{pH} 7$ 
3.6. Evaluation of the photolytic and the solar/ $\mathrm{H}_{2} \mathrm{O}_{2}$ processes

To evaluate the photolytic effect on the COD removal, the photocatalytic experiments are carried out under sunlight. The results reveal that the photolytic process is less efficient in the petroleum wastewater treatment, achieving an $8 \%$ COD removal at $\mathrm{pH} 7$ after $180 \mathrm{~min}$ of solar irradiation as shown in figure 3.

After the evaluation of the photolytic process, some experiments are carried out with adding $0.85 \mathrm{~g} \mathrm{~L}^{-1}$ Hydrogen peroxide $\left(\mathrm{H}_{2} \mathrm{O}_{2}\right)(35 \%(\mathrm{v} / \mathrm{v}))$, which is the optimum $\mathrm{H}_{2} \mathrm{O}_{2}$ concentration as determined previously (Aljuboury et al., 2015), to evaluate the effect of the Hydrogen peroxide $\left(\mathrm{H}_{2} \mathrm{O}_{2}\right)$ with solar radiation. The results reveal that $13 \%$ of COD is removed within $180 \mathrm{~min}$ at $\mathrm{pH} 7$ as shown in figure 3 . The removal is attributed to the photochemical cleavage of $\mathrm{H}_{2} \mathrm{O}_{2}$ by solar light absorption in result to increase rate of production hydroxyl radical $(\bullet \mathrm{OH})$ (Mendez-Arriaga et al., 2010).

\subsection{Treatment efficiency:}

Design Expert 6.0.7 software program (a statistical software package from Stat-Ease Inc) is used to determine optimization of COD removal efficiency and to assess the interactive relationship between the independent variables and the responses of certain models. 3D surface response plots are created by Design Expert 6.0.7 software program.

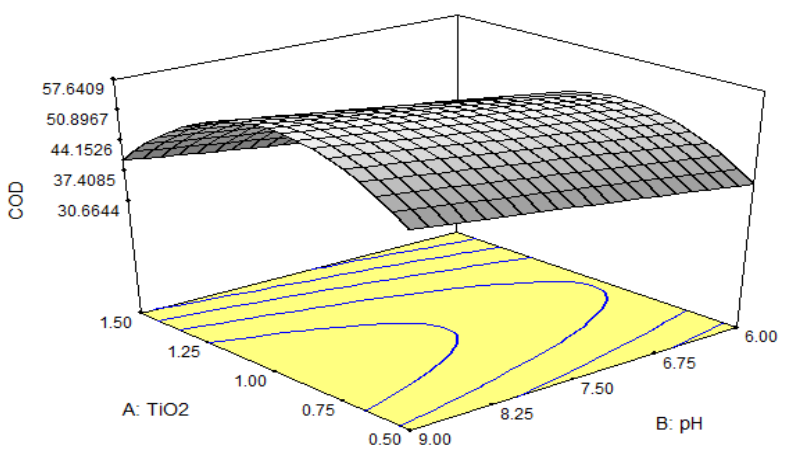

(a) The solar photocatalyst of $\mathrm{TiO}_{2}$

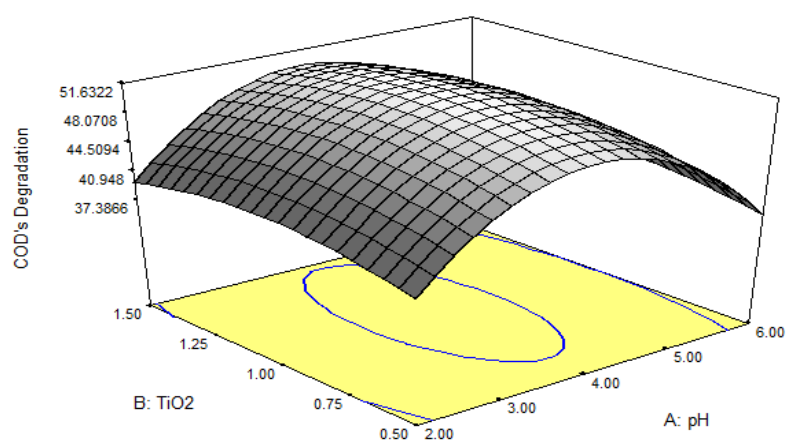

(b) The solar photocatalyst of $\mathrm{TiO}_{2} /$ Fenton

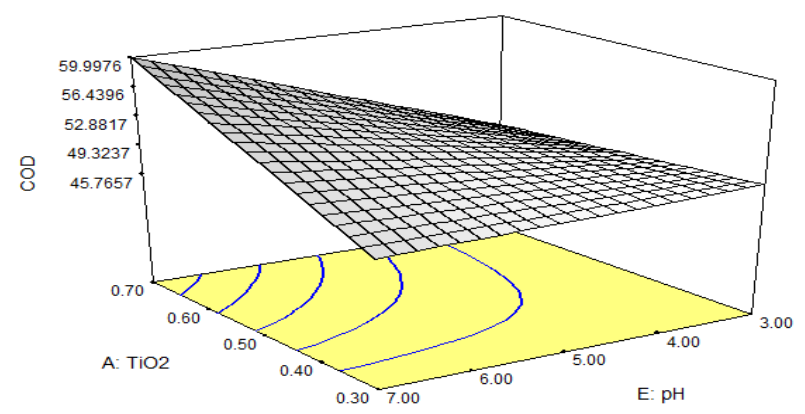

(c) The solar photocatalyst of $\mathrm{TiO}_{2} / \mathrm{ZnO} /$ Fenton

Figure 4. Effects of $\mathrm{TiO}_{2}$ and $\mathrm{pH}$ for $\mathrm{COD}$ removal efficiency in different processes 
The photo-Fenton coupled with $\mathrm{TiO}_{2} / \mathrm{ZnO}$ photocatalysis process is the most efficient neutral condition for treatment of petroleum wastewater. The highest removal rates of $\mathrm{COD}$ for the photo-Fenton coupled with $\mathrm{TiO}_{2}$ photocatalysis and the photo-Fenton are in acidic conditions. However, $\mathrm{TiO}_{2}$ photocatalysis is more efficient at alkaline conditions.

The current work reveals that $\mathrm{The}^{\mathrm{TiO}}{ }_{2}$ and $\mathrm{pH}$ were the two main factors that improved the COD removal for three processes $\left(\mathrm{TiO}_{2}\right.$ photocatalysis, photo-Fenton coupled with $\mathrm{TiO}_{2}$ photocatalysis and photo-Fenton coupled with
$\mathrm{TiO}_{2} / \mathrm{ZnO}$ photocatalysis) as shown in figure 4 . While the $\mathrm{Fe}^{+2}$ and $\mathrm{H}_{2} \mathrm{O}_{2}$ concentration are the main factors in the photo-Fenton process as shown in figure 5 .

Some interactions among variables are significant. Thus, the curvature of three-dimensional surfaces is obvious in the photo-Fenton process as shown in figure 5(a). Response plots in this process have clear peaks, meaning that the optimum condition for maximum values of the responses is attributed to all four variables such as $\mathrm{pH}$, $\mathrm{H} 2 \mathrm{O} 2$ dosage, $\mathrm{Fe}+2$ dosage and reaction time in the design space

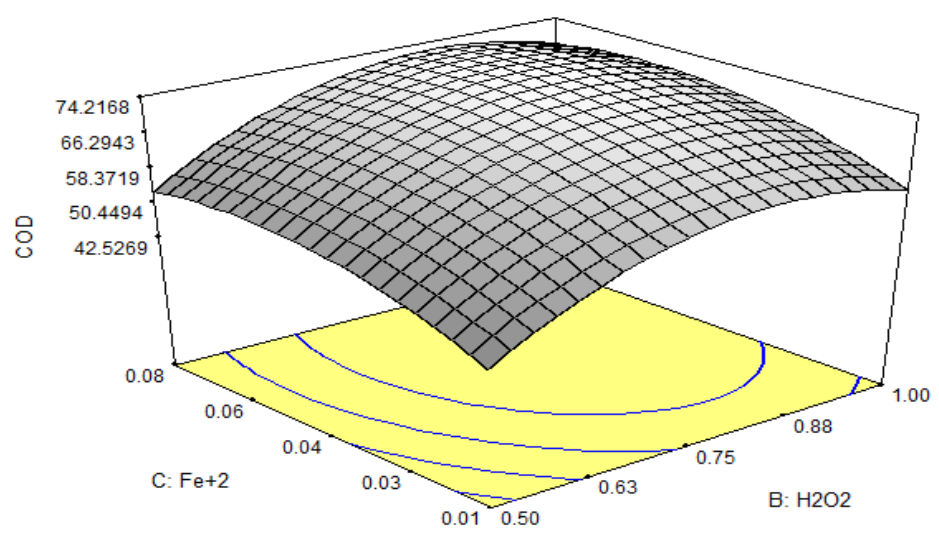

(a) The solar photocatalyst of Fenton

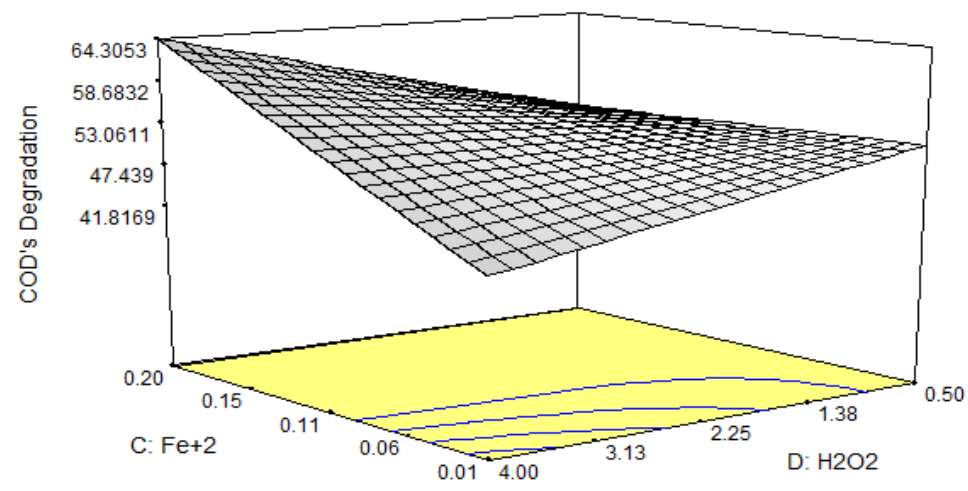

(b) The solar photocatalyst of Fenton/ $/ \mathrm{TiO}_{2}$

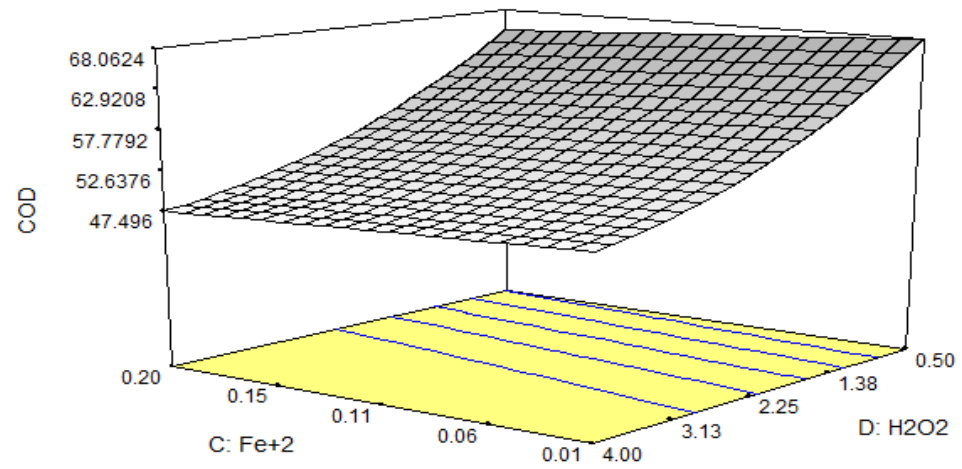

(c) The solar photocatalyst of $\mathrm{TiO}_{2} / \mathrm{ZnO} /$ Fenton

Figure 5. Effects of Fenton regents for COD removal efficiency in different processes 


\section{Conclusions}

In the present study, different oxidation processes such as the photo-Fenton, the $\mathrm{TiO}_{2}$ photocatalysis, the photoFenton coupled with $\mathrm{TiO}_{2}$ photocatalysis and the photoFenton coupled with $\mathrm{TiO}_{2} / \mathrm{ZnO}$ photocatalysis process are conducted to compare their performances in the treatment of petroleum wastewater by CCD with RSM. The photo-Fenton coupled with $\mathrm{TiO}_{2} / \mathrm{ZnO}$ photocatalysis process is the most efficient in the neutral conditions to remove COD from petroleum wastewater. Therefore, no need to adjust $\mathrm{pH}$ during this treatment. In acidic conditions $\mathrm{pH}<7$, the photo-Fenton process is more efficient than the $\mathrm{TiO}_{2}$ photocatalysis process. While it is less efficient than the $\mathrm{TiO}_{2}$ photocatalysis process in alkaline conditions $\mathrm{pH}>7$. The $\mathrm{TiO}_{2}$ dosage and $\mathrm{pH}$ are the main factors, which improve the COD removal in the $\mathrm{TiO}_{2}$ photocatalysis processes. While the $\mathrm{Fe}^{+2}$ and $\mathrm{H}_{2} \mathrm{O}_{2}$ concentration are the main factors in the photo-Fenton process.

\section{References}

Abu Amr S.S., Hamidi A.A., Mohd N.A. and Mohammed J.K. (2013), Optimization of semi-aerobic stabilized leachate treatment using ozone/Fenton's reagent in the advanced oxidation process, Journal of Environmental Science and Health, Part A, 48, 720-729.

Alaton I.A., Balcioglu I.A. and Bahnemann D.W. (2002), Advanced oxidation of a reactive dyebath effluent: comparison of $\mathrm{O}_{3}$, $\mathrm{H}_{2} \mathrm{O}_{2}$ /UV-C and $\mathrm{TiO}_{2} /$ UV-A processes, Water Research, 36, 1143-1154.

Aljuboury D.D.A., Palaniandy P., Abdul Aziz H.B. and Feroz S. (2015), Treatment of petroleum wastewater using combination of solar photo-two catalyst $\mathrm{TiO}_{2}$ and photoFenton process, Journal of Environmental Chemical Engineering, 3, 1117-1124.

Alhakimi G., Studnicki L.H. and Al-Ghazali M. (2003), Comparative photocatalytic degradation using natural and artificial UVlight of 4-chlorophenol as a representative compound in refinery wastewater, Journal of Photochemistry and Photobiology A: Chemistry, 157, 103-109.

Amor C., Torres-Socias E.D., Peres J.A., Maldonado M.I., Oller I., Malato S. and Lucas M.S. (2015), Mature landfill leachate treatment by coagulation/flocculation combined with Fenton and solar photo-Fenton processes, Journal of Hazardous Materials, 286, 261-268.

Boundjou G.D., Amouzou E., Kodom T., Tchakala I., Anodi K. and Bawa L.M. (2012), Photocatalytic degradation of orange II using mesoporous $\mathrm{TiO}_{2}$ (P25) and Fenton reactive, International Journal of Environmental Science, Management and Engineering Research, 1(2), 91-96.

Chou J.C. and Liao L.P. (2005), Study on pH at the point of zero charge of $\mathrm{TiO}_{2} \mathrm{pH}$ ion sensitive field effect transistor made by the sputtering method, Thin Solid Films, 476, 157-161.

Chong M.N., Jin B., Chow C.W.K. and Saint C. (2010), Recent developments in photocatalytic water treatment technology: A review, Water Research, 44, 2997-3027.

Da Silva S.S., Chiavone-Filho O., de Barros Neto E.L. and Foletto E. L. (2015), Oil removal from produced water by conjugation of flotation and photo-Fenton processes, Journal of environmental management, 147, 257-263.
Daneshvar N., Salari D. and Khataee A.R. (2004), Photocatalytic degradation of azo dye acid red 14 in water on $\mathrm{ZnO}$ as an alternative catalyst to $\mathrm{TiO}_{2}$, Journal of Photochemistry and Photobiology A, Chemistry, 162, 317-322.

Daniel G.L.M., Briones R.M.L., Su Chia-Chi and Lu Ming-Chun (2013), Kinetics of acetaminophen degradation by Fenton oxidation in a fluidized-bed reactor, Chemosphere, 90, 1444-1448.

De Luna M.D.G., Luna-Briones R.M., Chia-Chi S. and Ming-Chun L. (2013), Kinetics of acetaminophen degradation by Fenton oxidation in a fluidized-bed reactor, Chemosphere, 90, 1444-1448.

Diyauddeen B.H., Wan M.A., Wan D. and Abdul Aziz A.R. (2011), Treatment technologies for petroleum refinery effluents: $A$ review, Process Safety and Environmental Protection, 89, 95-105.

Duran A. and Monteagudo J.M. (2007), Solar photocatalytic degradation of reactive blue 4 using a Fresnel lens, Water Research, 41, 690-698, http://dx.doi.org/10.1016/j.watres.2006.06.042.17011017

Fernandez L., Lucas M.S., Maldonado M.I., Oller I. and Sampaio A. (2014), Treatment of pulp mill wastewater by Cryptococcus podzolicus and solar photo-Fenton, Chemical Engineering Journal, 245, 158-165.

Gaya U.I. and Abdullah A. (2008), Heterogeneous photocatalytic degradation of organic contaminants over titanium dioxide: a review of fundamentals, progress and problems, Journal of Photochemistry and Photobiology C: Photochemistry Reviews, 9, 1-12.

Ghassan Al-Sayyed, Jean-Christophe D'Oliveira and Pierre Pichat (1991), Semiconductor sensitized photo degradation of 4chlorophenol in water, Journal of Photochemistry and Photobiology A: Chemistry, 58, 99-114.

Giri A.S. and Golder A.K. (2014), Fenton, photo-Fenton, $\mathrm{H}_{2} \mathrm{O}_{2}$ photolysis, and $\mathrm{TiO}_{2}$ photocatalysis for Dipyrone oxidation: Drug Removal, mineralization, bio-degradability, and degradation mechanism. Industrial and Engineering Chemistry Research, 53, 1351-1358.

Gogniat G., Thyssen M., Denis M., Pulgarin C. and Dukan S. (2006), The bactericidal effect of $\mathrm{TiO}_{2}$ photocatalysis involves adsorption onto catalyst and the loss of membrane integrity, FEMS Microbiol. Letter, 258, 18-24.

Hermosilla D., Cortijo M. and Huang C. (2009), Optimizing the treatment of landfill leachate by conventional Fenton and photo-Fenton processes, Science of the Total Environment, 407, 3473-3481.

Herrmann W.A. (1996), Synthetic Methods of Organometallic and Inorganic Chemistry, 10, 140-141.

Jamil T.S., Gad-Allah T.A., Ali M.E.M. and Momb M.N.B. (2015), Utilization of nano size $\mathrm{TiO}_{2}$ for degradation of phenol enrich water by solar photocatalytic oxidation, Des. Water Treatment, 53, 1101-1106.

Kabir M.S., Lorenz M., Van Linn M.L., Namjoshi O.A., James S.A. and Cook M. (2010), A very active cu-catalytic system for the synthesis of aryl, heteroaryl, and vinyl sulfides, Journal of Organic Chemistry, 75, 3626-3643.

Khan W.Z., Najeeb I., Tuiyebayeva M. and Makhtayev Z. (2015), Refinery wastewater degradation with titanium dioxide, zinc oxide, and hydrogen peroxide in a photocatalytic reactor, Process Safety and Environmental Protection, 9, 479-486. 
Kim J.L., Lee H. and Lee C. (2012), Synergistic effects of $\mathrm{TiO}_{2}$ photocatalysis in combi-nation with Fenton-like reactions on oxidation of organic compounds at circumneutral $\mathrm{pH}$, Applied Catalysis B: Environmental, 115, 219-224.

Kwon S., Fan M., Cooper A.T. and Yang H. (2008), Photocatalytic applications of micro- and nano- $\mathrm{TiO}_{2}$ in environmental engineering, Critical Reviews in Environmental Science and Technology, 38, 197-226.

Legrini O., Oliveros E. and Braun A.M. (1993), Photochemical processes for water treatment, Chemical Reviews, 93, 671-698.

Lucas M.S. and Peres J.A. (2009), Removal of COD from olive mill wastewater by Fenton's reagent: kinetic study, Journal of Hazardous Materials, 168, 1253-1259.

Maltoand S., Caceres J., Aguera A., Mezcua M., Hernando D., Vial J. and Fernandez-Alba A.R. (2001), Degradation of imidacloprid in water by photo-Fenton and $\mathrm{TiO}_{2}$ photocatalysis at a solar pilot plant: A comparative study, Environmental Science and Technology, 35, 4359-4366.

Masomboon N., Chen C., Anotai J. and Lu M. (2010), A statistical experimental design to determine o-toluidine degradation by the photo-Fenton process, Chemical Engineering Journal, 159, 116-122.

Mendez-Arriaga F., Esplugas S. and Gimenez J. (2010), Degradation of the emerging contaminant ibuprofen in water by photo-Fenton, Water Research, 44(2), 589-595.

Montgomery D.C. (2008) Design and Analysis of Experiments. $7^{\text {th }}$ edition.

Nogueira R.F.P., Trovo A.G. and Paterlini W.C. (2004), Evaluation of the combined solar $\mathrm{TiO}_{2}$ /photo-Fenton process using multivariate analysis, Water Science and Technology, 49, 195-200.

Noordin V.C., Venkatesh S., Sharif S. and Elting A.A. (2004), Application of response surface methodology in describing the performance of coated carbide tools when turning AISI 1045 steel, Journal of Materials Processing Technology, 145, 46-58.

Paz D.S., Foletto E.L., Bertuol D.A., Jahn S.L., Collazzo G.C., da Silva S.S. and do Nascimento C.A. (2013), CuO/ZnO coupled oxide films obtained by the electrodeposition technique and their photocatalytic activity in phenol degradation under solar irradiation, Water Science and Technology, 68(5), 1031-1036.

Philippopoulos C.J. and Poulopoulos S.G. (2003), Photo-assisted oxidation of an oily wastewater using hydrogen peroxide, Journal of Hazardous materials, 98(1), 201-210.

Pignatello J.J., Oliveros E. and MacKay A. (2006), Advanced oxidation processes for organic contaminant destruction based on the Fenton reaction and related chemistry, Critical Reviews in Environmental Science and Technology, 36, 1-84.

Rossiter O., Rochaa S., Renato D.F., Marta M.M. and Duarte B. (2013), Solar photo-Fenton treatment of petroleum extraction wastewater, Desalination and Water Treatment, 51(28-30), 5785-5791.

Sakthivel S., Neppolian B., Shankar M.V., Arabindoo B., Palanichamy M. and Murugesan V. (2003), Solar photocatalytic degradation of azo dye: comparison of photocatalytic efficiency of $\mathrm{ZnO}$ and $\mathrm{TiO}_{2}$, Solar Energy Materials and Solar Cells, 77, 65-82.

Shahrezaei F., Mansouri Y., Zinatizadeh A.A.L. and Akhbari A. (2012), Process modeling and kinetic evaluation of petroleum refinery wastewater treatment in a photocatalytic reactor using $\mathrm{TiO}_{2}$ nanoparticles, Powder Technology, 221, 203-212.

Tekin H., Bilkay O., Ataberk S.S., Balta T.H. and Ceribasi I.H. (2006), Use of Fenton oxidation to improve the biodegradability of a pharmaceutical wastewater, Journal of Hazardous Materials, 136, 258-265.

Tony M.A., Zhao Y.Q., Purcell P.J. and El-Sherbiny M.F. (2009), Evaluating the photo-catalytic application of Fenton's reagent augmented with $\mathrm{TiO}_{2}$ and $\mathrm{ZnO}$ for the mineralization of an oilwater emulsion, Journal of Environmental Science and Health, Part A, 44, 488-493.

Wang X., Pehkonen S.O. and Ray A.K. (2004), Photocatalytic reduction of $\mathrm{Hg}(\mathrm{II})$ on two commercial $\mathrm{TiO}_{2}$ catalysts, Electrochimica Acta, 49, 1435-1444. 